\title{
Ruh Sağlığı Çalışanlarının Çeşitli Değiş̧kenler Açısından Karşılaştırması: Duygusal Emek, Psikolojik Sermaye ve İyi Oluş
}

\author{
DOI: $10.26466 /$ opus. 801638
}

\author{
Merve Mamac1 * \\ * Dr, İstanbul Kent Üniversitesi \\ E-Posta: merve.mamaci@kent.edu.tr \\ ORCID: $\quad \underline{0000-0001-7882-3670}$ \\ Öz
}

Bu çalışmanın amacl, ruh sağhlğı çalışanlarının mesleklerine göre psikolojik sermaye düzeylerini, duygusal emek stratejilerini ve psikolojik iyi oluş (PERMA) düzeylerini tespit etmek ve meslekler arası karşılaştırma yapmaktır. Bu araştırmaya, ruh sağhlğ̆ alanında aktif çalışma yaşamı olan 352 uzman katılmıştır. Veriler; 15 sorudan oluşan demografik bilgi formu, Luthans, Avolio, Avey ve Norman (2007) tarafindan geliştirilen, 21 sorudan oluşan psikolojik sermaye ölçeği, Diefendorff, Croyle ve Gosserland (2005) tarafindan geliştirilen, 13 maddeden oluşan duygusal emek ölçeği ve PERMA-TR ölçeği (Demirci, Ekşi, Dinçer ve Kardaş, 2017) vasıtasıyla elde edilmiştir. Analiz sonuçları, meslekler arası karşılaştırmada psikolojik danışmanların psikologlara ve psikiyatristlere göre anlamlı düzeyde psikolojik sermaye kaynaklarının yüksek olduğunu ortaya koymuştur. Duygusal emek stratejileri açısından meslekler arası karşılaştırma sonuçları ise psikiyatristlerin diğer ruh să̆lı̆̆ı çalışanlarına kıyasla anlamlı düzeyde yüzeysel rol yapma stratejisi kullandı̆̆ın göstermiştir. PERMA düzeyleri açısından meslekler arası anlamlı bir fark çıkmamıştır. Araşstırma sonucunda bulgular ilgili literatür ışığında tartışılmış, ve gelecek çalışmalar için öneriler sunulmuştur.

Anahtar Kelimeler: Ruh sağ lığı çalışanları, psikolojik sermaye, duygusal emek, iyi oluş 


\title{
A Comparison of Mental Health Workers in Terms of Various Variables: Emotional Labor, Psychological Capital and Well-being
}

\begin{abstract}
The purpose of this study is to compare the psychological capital levels, emotional labor strategies and PERMA levels of mental heal th professionals according to their occupations. 352 professionals who have active work life in the field of mental health participated in this research. The data was obtained through demographic information form, psychological capital scale Luthans, Avolio, Avey ve Norman (2007), emotional labor scale Diefendorff, Croyle ve Gosserland (2005) and PERMA-TR (Demirci, Ekşi, Dinçer ve Kardaş, 2017) scale. The results of the analysis revealed that psychological counselors have the highest level of psychological capital resources when compared to psychologists and psychiatrists. In terms of emotional labor strategies, it has shown that psychiatrists mostly use surface acting strategy compared to other mental health workers. It has found that there no significant difference in terms of PERMA levels. As a result of the research the findings were discussed in the light of the related literature, and suggestions for future studies were also presented.
\end{abstract}

Keywords: Mental health workers, psychological capital, emotional labor, well-being 


\section{Giriş}

Endüstri - Örgüt Psikolojisi ve Sosyal Psikoloji alanlarında duygusal emek, psikolojik sermaye ve psikolojik iyi oluş kavramlarının sıklıkla incelendiği görülmektedir. Her ne kadar bahsedilen kavramların farklı örneklemlerle incelendiği araştırmalar olsa da Türkiye' de ruh sağ lığı alanında çalışan kişilerin örneklem olarak kullanıldığı bir çalışma olmadığı görülmektedir. Türkiye'de aktif çalışma yaşamı olan ruh sağlığı çalışanlarının duygusal emek stratejilerinin tespit edilmesi, meslekler arası duygusal emek düzeylerinin karşılaştırılması ve farklı ruh sağlığı meslek gruplarının psikolojik sermaye ve psikolojik iyi oluş seviyelerinin karşılaştırılması, Türkiye'de var olan ruh sağlığı mensuplarının çalışma yaşamlarını anlama açısından fayda sağlayacaktır.

$\mathrm{Bu}$ araştırmada Türkiye'de ruh sağlığı alanında hizmet veren meslek grupları psikologlar, psikoterapistler, psikolojik danışmanlar (okul psikologları) ve psikiyatri hekimleri olacak şekilde incelenmiştir. Türkiye'de ruh sağlığı alanında hizmet veren belirli meslek gruplarının iş tanımlarının henüz netliğe kavuşmamış olması zaman zaman kavram kargaşalarına neden olmaktadır.

Bir meslek grubunun yaptığı işi tanımlamak için öncelikle iş analizi yapılması gerekmektedir. Böylelikle o meslekte çalışan kişilerin görevleri ve o işin hangi bilgi, beceri, yetkinliklere dayalı olduğu saptanabilir. O*Net (2020) tarafından gerçekleştirilen iş analizine dayanarak psikologların gözlem, görüşme ve psikolojik testler yoluyla bireylerin zihinsel ve duygusal bozukluklarını değerlendirdiği, teşhis ve tedavi sürecinde rol aldığı belirtilmektedir. Psikologlar bireylerin daha etkili kişisel, sosyal, eğitimsel ve mesleki gelişim sergilemlerine ve uyum becerilerinin geliştirilmesine yardımcı olmak için bireysel veya grup danışmanlık hizmetleri sağlarlar. Davranış değiştirme programları tasarlayabilirler. APA (2020) psikoterapistleri; zihinsel, duygusal ve davranışsal bozuklukları psikolojik yollarla tedavi etmek için profesyonel olarak eğitilmiş ve lisans almış bir profesyonellerdir. Ayrıca klinik psikologlar, psikiyatristler, danışmanlar, sosyal hizmet uzmanları veya psikiyatri hemşiresleri psikoterapist olabilirler. O*Net'e göre (2020) psikolojik danışmanlar; bir okuldaki eğitim işlevini olumsuz yönde etkileyen eğitimsel, davranışsal veya gelişimsel sorunları ele almak için bireysel veya okul çapında müdahaleleri veya stratejileri teşhis ederler ve uygularlar. Öğrencilerin öğ- 
renme ve davranış sorunlarını ele alabilirler ve öğrencilere veya ailelere rehberlik edebilirler. Performans planları tasarlayıp uygulayabilirler ve performansı değerlendirebilirler. Psikiyatristler ise; ruhsal bozuklukları teşhis ederler, tedavi ederler ve bu bozuklukları önlemeye yardımcı olurlar.

\section{Literatür}

Endüstri ve örgüt psikolojisi çerçevesinde yaşamda önem arz eden kaynaklar ekonomik, sosyal veya insan kaynağı olarak çeşitlilik göstermektedir. Örgütsel psikoloji ve pozitif psikoloji alanlarında sıklıkla araştırma konusu olarak seçilen psikolojik sermaye kavramı aynı zamanda iş sonuçlarını olumlu yönde etkileyen bireye özgü bir kaynak olarak değerlendirilmektedir. Bireylerin psikolojik sermayeleri bireyler ve çalıştıkları örgütler açısından uzun vadeli rekabet avantajı sağlayan ve geliştirilmeye açık bir yapı olarak tanımlanmaktadır (Luthans ve Youssef, 2004). Psikolojik sermaye dört farklı alt boyuttan oluşan bir yapıdır ve bu alt boyutlar; özyeterlik, umut, iyimserlik ve psikolojik dayanıklılıktır. Buna karşın psikolojik sermayenin bu dört alt boyutun toplamından daha farklı ve kapsamlı bir kavram olduğu belirtilmektedir (Luthans, Avolio, Avey, ve Norman, 2007).

Özyeterlik; ilk kez Bandura (1977) tarafından Sosyal Bilişsel Kuramı'nın bir öğesi olarak ortaya atılmıştır ve bireylerin içinde oldukları durumlarla başa çıkabilmek için göstermeleri gereken davranışlardaki başarı düzeylerine ilişkin inançları olarak tanımlanmıştır. Dolayısıyla özyeterlik, bireylerin bir işi yapabileceklerine dair olan inançları olarak ele alınabilir. Psikolojik sermayenin ikinci alt boyutu olan umut, Synder (1994) tarafından geliştirilen Umut Kuramı'nda iki bilişsel öğenin etkileşimine dayanan motivasyon hali olarak belirtilmektedir. Bu öğeler; oluşturulacak yola dair düşünce ve bireyin düşüncesidir. Yola dair düşünce, kişinin bir hedefi gerçekleştirmeye yönelik etkili ve yararlı yollar oluşturma kapasitesi hakkındaki algıları anlamına gelmektedir. Bu algı, bireyin belirli bir hedefe ulaşmak için pratik bir eylem planı geliştirmesini ve izlemesini içermektedir. Ayrıca başlangıçtaki hedefin düşünüldügü kadar etkili olmaması veya hedefin takibinde bir engel tarafından durdurulması halinde alternatif planlar geliştirmesi olarak da öne sürülmüştür (Snyder, 1994). Psikolojik sermayenin üçüncü alt boyutu olan iyimserlik, Youseff ve Luthans'a göre (2007) bireyin olumlu olayları, kişisel (kişiye özgü), kalıcı, yaygın (durumla ilişkili olmayan) ve olumsuz olayları, çevresel, geçici 
ve duruma özgü olarak yorumlamasıdır. Son boyut olan Psikolojik dayanıklılk; olumsuz olaylar karşısında adaptasyon ve baş etme becerisi olarak tanımlanmaktadır (Masten, 2001). Youssef ve Luthans (2007)'e göre psikolojik dayanıklılığı yüksek olan kişiler stresli durumları uyarlayabilir ve aynı zamanda zorlu deneyimlerden motivasyon sağlayabilirler.

Türkiye'deki ve dünyadaki alan yazın incelendiğinde psikolojik sermayenin iyi oluşla ve iş performansıyla ilişkisine dair farklı örneklemlerle gerçekleştirilmiş çeşitli araştırmalar olduğu görülmektedir (Korkmazer, Ekingen ve Yıldız, 2016; Polatçı, 2011; Demir, 2018; Avcı ve Bozgeyikli, 2017; Cankir ve Şahin, 2018; Çankır, 2019; Arikan ve Çankır, 2019;). Bu sebepten Türkiye'de aktif çalışma yaşamı olan ruh sağlığı çalışanlarının psikolojik sermaye düzeylerinin saptanmasının ruh sağlığı hizmetlerinin geliştirilmesi ve çalışanların psikolojik iyi oluşlarının iyileştirmeye yönelik planlamanın yapılmasına vesile olabileceği düşünülebilir.

Ruh sağllğı uzmanlarının meslek yaşamları ile ilişkilendirilebilecek bir diğer kavram duygusal emektir. Hochschild $(1979,1983)$ tarafından terminolojiye kazandırılan duygusal emek kavramı ile duygu işçiliğinin teorik ve kavramsal bir çerçevesi öne sürülmüştür. Hochschild (1983)' e göre duygusal emek; bireyin bireysel duygularını sahip olduğu meslek ve içinde bulunduğu örgüt çerçevesinde uygun normlara göre düzenlemesidir. Duygulanım kuralları, duygu işçiliğini bir diğer deyişle ne zaman, nerede ne hissedileceğini yönlendirir. Duygusal emek sürecinde kişi bedensel ifadelerini, mimiklerini normlara göre düzenlemektedir. Birey tarafından gösterilen bu çaba aynı zamanda ekonomik değer taşımaktadır çünkü örgütsel hedefleri gerçekleştirmek için bu çaba sarf edilmektedir. Hochschild' e göre (1983) hizmet sektörü adeta şov sahnesine benzer ve çalışanlar sahnedeki aktörlerdir. Bu anlamda çalışanların iki farklı yol izleyerek duygu yönetimi gerçekleştirebilmektedir. İlk strateji yüzeysel rol yapmadır (YRY). Yüzeysel rol yapma stratejisi uygulayan çalışanlar, gerçekte hissettikleri duyguları değiştirmezler ancak dışarıya yansıttıkları ifadeleri değiştirirler. Örneğin ruh sağlığı alanında hizmet veren bir uzman danışanının travmatik yaşam deneyimleri sunan bir danışan karşısında üzüntü hissetmeyebilir ama dışarıdan bakıldığında üzülmüş izlenimi yaratacak bir ifade yaratabilir. Bunu bedensel, mimik, ses tonu gibi araçlarla gerçekleştirebilir. Tahmin edileceği üzere YRY stratejisinde gerçekte yaşanılan duygu ve dışarıya yansıtılan duygu arasında tutarsızlık olduğu için çalışan bilişsel çelişki ve duygusal çelişki yaşamaktadır. Hochschild (1983) 
duygu yönetimi için başvurulan ikinci strateji olarak derin rol yapma (DRY) boyutunu öne sürmektedir. Buna göre; çalışanlar derin rol yapma sürecinde çevreye uygun duyguyu ortaya koyabilmek için gerçekte hissettikleri duyguları bilinçli olarak değiştirmektedirler. Böylelikle ortaya çıkan yeni duygu hem hizmet alan kişinin beklentisine uygun olmaktadır hem de çalışan için otantik bir duygu değeri taşmaktadır. Groth, Hennig-Thurau ve Walsh (2009)'a göre derin rol yapma stratejisi uygulayan çalışanlar ilk hissettikleri duyguyu değiştirirler ve yeni bir duygu ortaya çıkartırlar. Derin rol yapma, var olan duyguların yerine uygun olan ve gösterilmesi beklenen duyguların yer almasıdır (Lui, Prati, Perrewe ve Brymer, 2010). Duygusal emeğin üçüncü alt boyutu olan doğal duygular (DD) Ashforth ve Humphrey (1993) tarafından ileri sürülmüştür. Doğal duygular stratejisinde çalışanın var olan duygusunu değiştirmek için her zaman bilinçli bir çaba göstermeyebileceği vurgulanmaktadır. Buna göre çalışan gerçekte hissettiği duyguyu karşı tarafa yansıtmaktadır. Bu bilgilerden yola çıkarak ruh sağlığı çalışanlarının duygusal emek stratejilerinin incelenmesi ve meslekler arası strateji farklılıklarının var olup olmadığının test edilmesinin alana katkı sağlayacağı düşünülmüştür.

Gerek fiziksel iyi oluş gerek psikolojik iyi oluş insan yaşamında önemli bir yer tutmaktadır. Dünya Sağlık Örgütü (1998) sağlığı "sadece herhangi bir hastalığın ya da bozukluğun olmayışı değil, aynı zamanda zihinsel, bedensel, ruhsal ve sosyal açıdan tam iyilik hali" olarak tanımlamaktadır.

Tarihsel açıdan incelendiğinde filozofların ve psikologların üzerinde çalıştıkları konular itibariyle benzerlik gösterdikleri söylenebilir. İyi oluş kavramı, filozofların fikirlerinden beslenilerek psikologlar tarafından da incelenmektedir (Kahneman, 1999; Waterman, 1993). Waterman (2008)' e göre psikolojik iyi oluş kavramının bir öğesi olan hedonik yaklaşım (öznel iyi oluş), Aristippus, Epicurus, Bentham, Locke, ve Hobbes gibi filozofların görüşlerine kadar dayanmaktadır. Diener (2009), hedonia kavramının filozoflar tarafından iyi oluşla ve arzuların tatmin edilmesiyle ortaya çkan olumlu duygu durumla ilişkilendirildiğini öne sürmüştür. Buna göre; haz, üzüntülü olmama hali, yaşamdan alınan lezzet hedonik iyi oluşun yansımalardır. Hedonik yaklaşımdan bahseden filozoflar, insanın hazzı maksimize edip acıyı minimize etme eğilimi olduğunu öne sürmüşlerdir. Dolayısıyla haz ve acı, iyi ya da kötü yaşamın belirleyicileridir. Hedonik yaklaşıma karşıt olarak ortaya çıkmış olan eudaimonia görüşü Aristoteles tarafından öne sürülmüştür, ancak bu kavramın tarihi Plato ve Zenon'a kadar uzanmaktadır (Grinde, 2012). 
Aristoteles'e göre akıl yoluyla, tefekkürle, erdemlerle dolu ve kişinin kendine has otantisitesiyle beraber sürdürdüğü yaşam iyi oluşa giden yolun yapı taşlardır (Norton, 1976). Aristoteles, erdemli olmayı asalet, nezaket, cesaret, dürüstlük içinde davranışlar sergilemek ve bu davranış biçimini sadece öyle olması gerektiği için uygulamak olarak tanımlamıştır. Kişinin kendi potansiyelini kendisi için ve toplum için geliştirmesini iyi yaşamın ayırıcı özelliği olarak öne sürmüştür (Keyes ve Annas, 2009). Haz ve iyi yaşam Aristoteles tarafından farklı kavramlar olarak ele alınmıştır. Haz odaklı bir yaşam aynı zamanda kölelik anlamına gelmektedir. Bu bakış açısına göre sadece olumlu duygulardan oluşan bir yaşam, iyi yaşamın temeli olarak görülemez. Buna karşılık eudaimonik (erdemli) yaşamın sonucunda olumlu duyguların erdemle yaşamanın bir sonucu olarak ortaya çıkacağı vurgulanmıştır (Kashdan, Diener ve King, 2008). Waterman' a göre (2008) Aristoteles hazzı değil, ancak hazzın elde edilmesinin sadece haz elde etmek için oluşunu reddetmektedir. Hedonia, öznel bir yaklaşım olmasına karşın, Aristoteles' in eudaimonia kavramı objektif bir yaklaşımdır. Aristoteles erdemli bir yaşam sürebilmenin kriterlerini öne sürerek bireyin yaşamına dışarıdan bakıldığında ne derece erdemli (iyi bir yaşam) sürdüğünü anlaşılabilir kılmıştır (McDowell, 1980). Bu yaklaşıma göre, hazza dayalı mutluluk ve doyum, kınanması gereken bir davranış olmakla beraber kişinin öznel olarak betimlediği mutluluk ve doyum iyi bir yaşamın göstergesi olmamaktadır. Eudaimonik görüşle ilgilenen filozoflar kişinin mutlu olup olmadığından ziyade, hangi yollarla iyi bir yaşam sürdüğünü merak etmişlerdir (Henderson ve Knight, 2012).

Alan yazında psikolojik iyi oluşla ilişkili araştırmalar hedonik ve eudaimonik bakış açısını içeren kuramlarla ele alınmaktadır. Hedonia, haz arayışı anlamına gelmektedir (Huta, Park, Peterson ve Seligman, 2006) ve "öznel iyi oluş" olarak isimlendirilmektedir (Diener ve Ryan, 2009). Öznel iyi oluş, olumlu ve olumsuz duygulanım, biliş (kişinin yaşam alanlarını değerlendirmesi ve doyumu hakkında düşünceye sahip olması) öğelerini içermektedir (Diener, 2009). Eudaimonia, bireyin ideal işlevselliğini ve yaşamda anlamlı hedeflere ulaşma çabasını ifade eder (Huta, Park, Peterson ve Seligman, 2006). Keyes' göre (2007) iyi oluş; hedonik ve eudaimonik faktörlerinin bütünüyle açılanabilir.

Seligman (2011) tarafından geliştirilen PERMA modeli, hedonik ve eudaimonik bakış açılarını kapsayan bir psikolojik iyi oluş modelidir. PERMA, beş alt boyuttan oluşmaktadır. Bu boyutlar; (P) positive feelings; olumlu duygular 
(E) engagement; bağlanma, (R) relationships; ilişkiler, (M) meaning; anlam, (A) accomplishment; başarı olarak belirtilmiştir. PERMA alt boyutları birbirlerinden ayrı olarak tanımlanabilir ve ölçülebilir olsalar da (Lovett ve Lovett, 2016) tek başlarına genel iyi oluşu ifade etmemektedirler (Seligman (2011). Modelin önemli bir özelliği ise Türkiye'de kullanılmamış olmasıdır.

Diğer insanların yaşamlarına dokunan ruh sağlığı çalışanlarının psikolojik iyi oluş seviyelerinin psikolojik iyi oluş seviyelerinin her iki iyi oluş bak1şını içeren bir modelle ölçülmesi, PERMA modelinin Türkiye'ye tanıtılması, ruh sağlığı çalışanlarının ve psikolojik iyi oluşun meslekler arası karşılaştırılması alan yazına zenginlik katacağı düşünülmüştür.

\section{Yöntem}

\section{Katılımcilar}

Araştırmaya 322 psikolog, 39 psikoterapist, 63 psikolojik danışman, 21 psikiyatri hekimi ve kendisini diğer meslek dallarıyla ifade eden 7 ruh sağlığ lışanı katılmıştır. Toplam katılımcı sayısı 352' dir. Araştırmaya katılan uzmanlardan 90 kişi yarı zamanlı ve 262 kişi tam zamanlı olarak çalışmaktadır. Katılımclların 38'i erkek ve 314'ü kadındır. Katılımcıların 54'ü iş yerinin sahibi ve 298 'i iş yerinde çalışan olduğunu ifade etmiştir.

\section{Veri Toplama Araçları}

Demografik Bilgi Formu: Demografik bilgi formu araştırmaya katılan ruh sağlığı çalışanlarının sosyo-demografik özelliklerini değerlendirmeye yönelik 15 sorudan oluşmaktadır. Bu sorular; cinsiyet, yaş, ilişki durumu, eğitim durumu, meslek, çocuk sahibi olunup olunmadığı, çalışılan kurumun yapısı (kamu-özel), iş yerinin sahibi olunup olunmadığı, uzmanlık alanı, mesleki çalışma alanı, çalışma durumu (yarı zamanlı-tam zamanlı), çalışılan sektör, genel iş deneyimi süresi ve bulunduğu iş yerindeki çalışma süresi gibi konuları içermektedir.

Duygusal Emek Ölçeği: Duygusal Emek Ölçeği Diefendorff, Croyle ve Gosserland (2005) tarafından geliştirilmiştir ve Basım ve Beğenirbaş (2012) tarafından Türkiye normlarına uyarlanmıştır. Ölçek 13 maddeden ve 3 boyuttan oluşan ölçeğin bu araştırmada toplam Cronbach $\alpha$ değeri .75, yüzeysel rol yapma boyutu .86 , derin rol yapma boyutu .88 ve doğal duygular .77 olarak 
bulunmuştur. Bu değer ölçeğin iç güvenirliğinin yeterli olduğunu göstermektedir. Bu araştırmada katılımclar puanlama sistemi orijinal ölçekte olduğu gibi beşli Likert Skalasına göre değerlendirilmişlerdir.

Psikolojik Sermaye Ölçeği : Psikolojik Sermaye Ölçeği Luthans, Avolio, Avey ve Norman (2007) tarafından geliştirilen ve Çetin ve Basım (2012) tarafından Türkçe'ye uyarlanan ölçek toplam 21 sorudan ve 4 boyuttan oluşmaktadır. Puanlama sistemi altılı Likert Skalası olarak kullanılmıştır. Ölçeğin alt boyutlarının cronbach $\alpha$ değeri iyimserlik için .75, psikolojik dayanıklılık için .69, umut için .74, ve öz yeterlilik için .80 olarak bulunmuştur. Ölçeğin toplam Cronbach alfa güvenirlilik katsayısının .90 olduğu görülmektedir. Buna göre ölçeğin iç güvenirlilik açısından yeterli olduğu söylenebilir.

PERMA-TR Ölçeği : PERMA-TR Ölçeği Butler ve Kern (2016) tarafından geliştirilmiştir ve Demirci, Eksi, Dincer ve Kardas (2017) tarafından Türkiye normlarına uyarlanmıştır. PERMA Ölçeği, Martin Seligman tarafından öne sürülen psikolojik iyi oluşun 5 boyutlu yapısını değerlendirmeyi amaçlamaktadır. Bu boyutlar; olumlu duygular, bağlanma, olumlu ilişkiler, anlam ve başarıdır. Katılımcılar onbirli Likert Skalası çerçevesinde değerlendirilmişlerdir. Olumlu duygular, bağlanma, ilişkiler, anlam, ve başarı alt boyutları ile hesaplanan PERMA-TR ölçeğinin toplam Cronbach $\alpha$ değeri .89'dur. Alt boyutların güvenirlikleri; olumlu duygular için .87, bağlanma için .66, ilişkiler için .64, anlam için .72, başarı için .67'dir. Psikolojik iyi oluşu hedonik ve eudaimonik yönelimle ölçen bu ölçeğin iç güvenirlilik katsayısı ölçeğin kullanılabilir olduğunu göstermektedir.

\section{İşlem}

İstanbul ilinde Ocak-Ekim 2018 tarihleri arasında EMDR (Göz Hareketleriyle Duyarsızlaştırma ve Yeniden İşleme) eğitimi alan ve aktif çalışma yaşamı olan ruh sağlığı çalışanlarına alacakları eğitim öncesi duyuru yapılarak kattlım sağlamak isteyen kişilere ölçekler aynı gün içinde dağıtılmıştır. Ölçekler, aynı gün sonunda katılımcılar tarafından doldurulan onam formlarıla birlikte teslim alınmıştır. 


\section{Verilerin Analizi}

Araştırmanın amaçlarına uygun olarak toplanan veriler SPSS v.21 (Statistical Package for Social Sciences) programı ile istatistiksel analize tabi tutulmuştur. Demografik bilgiler kategorilere ayrılarak dağılımları frekans analizi ile hesaplanmıştır. Analiz öncesi normallik testi (Kolmogorov-Smirnov ve Shapiro Wilk) uygulanmış ve normal dağılım görülmemiştir. Çarpıklık ve basıklık değerleri olan Skewness ve Kurtosis değerlerinin -1.5 ve +1.5 aralığında olduğu gözlenmiştir. Katılımcıların mesleklerine göre ölçeklerden aldıkları ortalama puanların karşılaştııılması Kruskal Wallis testi ve Mann Whitney U testi ile gerçekleştirilmiştir.

\section{Bulgular}

\section{Demografik Özellikler Açısından Karşılaştırma}

Bu başlık altında katılımcıların bir demografik özellik olarak meslek bakımından Duygusal Emek Ölçeği'nden, Psikolojik Sermaye Ölçeği'nden ve PERMA Ölçeği'nden aldıkları ortalama puanlar, standart sapmalar ve normal dağılım göstermeyen örnekleme uygun Kruskal Wallis testi ve Mann Whitney U testi bulguları karşılaştırılmıştır.

\section{Duygusal Emek Ölçeği Açısından Meslekler Arası Karşılaştırma}

Tablo 1. Duygusal Emek Ölçeği Açısından Meslekler Arası Karşılaştırma

\begin{tabular}{|c|c|c|c|c|c|c|}
\hline & & $\mathrm{N}$ & ORT & SS & $\chi^{2}$ & $\mathrm{p}$ \\
\hline \multirow{4}{*}{ YRY } & Psikolog & 222 & 12.18 & 4.451 & \multirow{4}{*}{16.347} & \multirow{4}{*}{$.001^{*}$} \\
\hline & Psikoterapist & 39 & 11.54 & 4.489 & & \\
\hline & PDR & 63 & 10.81 & 4.028 & & \\
\hline & Psikiyatrist & 21 & 15.05 & 4.141 & & \\
\hline \multirow{4}{*}{ DRY } & Psikolog & 222 & 19.94 & 2.418 & \multirow{4}{*}{17.279} & \multirow{4}{*}{$.001^{*}$} \\
\hline & Psikoterapist & 39 & 19.28 & 2.235 & & \\
\hline & PDR & 63 & 21.05 & 1.717 & & \\
\hline & Psikiyatrist & 21 & 19.76 & 2.300 & & \\
\hline \multirow{4}{*}{ DD } & Psikolog & 222 & 11.91 & 1.679 & \multirow{4}{*}{6.241} & \multirow{4}{*}{.100} \\
\hline & Psikoterapist & 39 & 12.10 & 1.553 & & \\
\hline & PDR & 63 & 12.46 & 1.584 & & \\
\hline & Psikiyatrist & 21 & 11.67 & 1.238 & & \\
\hline
\end{tabular}

${ }^{*} \mathrm{p}<.05$ 
Yapılan analizler sonucunda katılımcıların mesleklerine göre YRY alt ölçeğinden aldıkları ortalama puanlar arasında anlamlı fark olduğu görülmüştür $\left[\chi^{2}(3)=16.347 ; p=.001\right]$. Farkın kaynağının tespit edilmesi amacıyla gerçekleştirilen Mann Whitney U testi sonucunda psikologların YRY ortalamaları (ort=12.18) psikolojik danışmanların ortalamalarından (ort=10.81) anlamlı şekilde yüksek bulunmuştur [ $\mathrm{z}=-2.197 ; \mathrm{p}=.028]$. Psikiyatristlerin YRY ortalamalarının (ort=15.05) psikologların ortalamalarından (ort=12.18) anlamlı şekilde yüksek olduğu tespit edilmiştir [ $\mathrm{z}=-2.918 ; \mathrm{p}=.004]$. Ayrıca psikiyatristlerin YRY ortalamalarının (ort=15.05) psikoterapistlerin ortalamalarından (ort=11.54) anlamlı şekilde yüksek olduğu [ $z=-3.210 ; p=.001]$ ve psikolojik danışmanların ortalamalarından (ort=10.81) anlamlı şekilde yüksek olduğu anlaşılmıştır [ $\mathrm{z}=3.835 ; \mathrm{p}=.000]$.

DRY stratejisi incelendiğinde katılımcıların mesleklerine göre DRY alt ölçeğinden aldıkları ortalama puanlar arasında da anlamlı fark olduğu gözlenmiştir [ $\left.\chi^{2}(3)=17.279 ; p=.001\right]$. Mann Whitney $U$ testi sonucuna göre, psikolojik danışmanların DRY ortalamalarının (ort=21.05) psikologların ortalamalarından (ort=19.94) anlamlı şekilde yüksek olduğu ortaya çıkmıştır [z=-3.412; $\mathrm{p}=.001$ ]. Psikolojik danışmanların DRY ortalamaları (ort=21.05) psikoterapistlerin ortalamalarından da (ort=19.28) anlamlı şekilde yüksek bulunmuştur $[\mathrm{z}=-3.918 ; \mathrm{p}=.000]$. Son olarak, psikolojik danışmanların DRY ortalamalarının (ort=21.05) psikiyatristlerin ortalamalarından da (ort=19.76) anlamlı şekilde yüksek olduğu görülmüştür [ $\mathrm{z}=-2.041 ; \mathrm{p}=.041]$. Katılımcıların mesleklerine göre DD alt ölçeğinden aldıkları ortalama puanlar arasında anlamlı fark bulunmadı̆̆1 tespit edilmiştir $\left[\chi^{2}(3)=6.241 ; p=.100\right]$.

\section{Psikolojik Sermaye Ölçeği Açısından Meslekler Arası Karşılaştırma}

Tablo 2. Psikolojik Sermaye Ölçeği Açısından Meslekler Arası Karşılaştırma

\begin{tabular}{|c|c|c|c|c|c|c|}
\hline & & $\mathrm{N}$ & ORT & SS & $\chi^{2}$ & $\mathrm{p}$ \\
\hline \multirow{4}{*}{$\begin{array}{l}\text { Psikolojik Ser- } \\
\text { maye }\end{array}$} & Psikolog & 222 & 101.21 & 10.203 & \multirow{4}{*}{10.887} & \multirow{4}{*}{$.012^{*}$} \\
\hline & Psikoterapist & 39 & 101.72 & 8.971 & & \\
\hline & PDR & 63 & 105.67 & 9.788 & & \\
\hline & Psikiyatrist & 21 & 98.86 & 10.297 & & \\
\hline
\end{tabular}

${ }^{*} \mathrm{p}<.05$

Ruh sağlı̆̆ı çalışanlarının mesleklerine göre Psikolojik Sermaye Ölçeğinden aldıkları toplam puan ortalamaları arasında anlamlı fark tespit edilmiştir 
$\left[\chi^{2}(3)=10.887 ; p=.012\right]$. Mann Whitney U testi sonuçlarına göre, psikolojik danışmanların psikolojik sermaye ortalamalarının (ort=105.67) psikologların ortalamalarından (ort=101.21) anlamlı şekilde yüksek olduğunu göstermiştir [ $\mathrm{z}=-3.012 ; \mathrm{p}=.003]$. Ayrıca Psikolojik danışmanların psikolojik sermaye ortalamalarınin (ort=105.67) psikiyatristlerin ortalamalarından da (ort=98.86) anlamlı şekilde yüksek olduğu anlaşılmıştır [ $\mathrm{z}=-2.507 ; \mathrm{p}=.012]$.

\section{PERMA-TR Ölçeği Açısından Meslekler Arası Karşılaştırma}

Tablo 3. PERMA-TR Ölçeği Açısından Meslekler Arası Karşılaştırma

\begin{tabular}{lllllll}
\hline & & $\mathrm{N}$ & ORT & SS & $\chi^{2}$ & $\mathrm{p}$ \\
\hline \multirow{4}{*}{ PERMA } & Psikolog & 222 & 7.62 & .919 & & \\
\cline { 2 - 5 } & Psikoterapist & 39 & 7.58 & .853 & .017 & .260 \\
\cline { 2 - 5 } & PDR & 63 & 7.78 & .966 & .936 \\
\cline { 2 - 5 } & Psikiyatrist & 21 & 7.39 & & \\
\hline
\end{tabular}

${ }^{*} \mathrm{p}<.05$

Katılımcıların mesleklerine göre, PERMA ölçeğinden aldıkları ortalama puanlar açısından değerlendirildiğinde meslekler arası anlamlı fark bulunmadığı gözlenmiştir.

\section{Tartışma ve Sonuç}

Araştırma sonuçları incelendiğinde yüzeysel rol yapma ve derin rol yapma alt boyutları çerçevesinde meslekler arası düzeyde anlamlı düzeyde farklılık olduğu, buna karşın doğal duygular açısından mesleklerarası anlamlı düzeyde bir fark tespit edilmediği görülmüş̧tür.

Psikiyatristlerin, diğer meslek grupları içerisinde en yüksek düzeyde yüzeysel rol yapma (YRY) deneyimi olan meslek grubu olduğu gözlenmiştir. İkinci strateji olarak değerlendirilen derin rol yapma (DRY) incelendiğinde psikolojik danışmanların, diğer meslek gruplarına kıyasla en yüksek puanı aldığı görülmüsstür. Buradan yola çıkarak psikiyatri hekimlerinin çalışma yaşamlarında gerçekte hissettikleri duyguları koruyarak sadece bedensel ifadeler, mimik, jest ve ses tonu üzerinden karşı tarafa farklı bir duygu yansıttığı söylenebilir. Psikolojik danışmanlar ise çalışma yaşamlarında çevrelerine uygun duygulanım sergileyebilmek için var olan duygularını bilinçli olarak değiştirerek yeni bir duygu yaratmaktadırlar. 
Morris ve Feldman (1996) örgütsel özelliklerin, iş özelliklerinin ve bireysel farklılıkların duygusal emeğin öncülleri olduğunu öne sürerek duygusal gösterim süresinin ve duygu yoğunluğunun fazla olduğu iş kollarında, bireylerin daha fazla çaba (duygu işçiliği) gösterdiğini belirtmektedir. Meslekler arası düzeyde farklı duygusal emek stratejilerinin açısından anmalı düzeyde fark olması bahsedilen değişkenlerin çalışanların iş ve özel yaşamına etkisinden kaynaklanıyor olabilir. Ayrıca çalışma yaşamında gösterilmesi beklenen duygular çeşitlilik gösteriyorsa ve kısa zaman içerisinde farklı duyguların sergilenmesi gerekiyorsa çalışanın duygusal emek düzeyi artmaktadır. Bu noktadan yola farklı ruh sağlığ 1 mesleklerinin iş özellikleri, iş yerinde duygusal gösterimin sıklığı, yaşanılan duyguların yoğunluğu, duyguların gösterilme süresi, gösterilmesi beklenen duyguların çeşitliliği ve ruh sağlığı profesyonellerinin meslekleri ile ilgili algıladıkları roller incelenmeye değerdir. Çalışma şartlarının da duygusal emek stratejilerini etkileyebileceği düşünülebilir. Örneğin ruh sağlığı çalışanın gün içinde gördüğ̈̈̈ hasta/danışan sayısı, günde kaç saat çalıştığı, vardiyalı ya da vardiyasız çalışma şekli, iş üzerinde hissettiği kontrol derecesi, nöbete kalıp kalmaması duygusal emek stratejilerinin meslekler arası düzeyde farklılaşmasıyla ilişkili olabilir.

Bireysel farklılıkla ilişkilendirilebilecek değişken olarak duygusal zeka, duygusal emek kavramının öncülleri arasında literatürde sıklıkla incelenmektedir. Salovey ve Mayer (1990) duygusal zeka seviyesi yüksek olan kişilerin kendi duygularını ve başkalarının duygularını anlayabilme ve kendi duygularını ifade edebilme kapasitesinin yüksek olduğunu öne sürmüştür. Buna göre kişinin duygusal zeka kapasitesi düşük ise bireyler duygularını ifade etmekten imtina edebilir veya sadece ifadesini değiştirebilir. Wong ve Law (2002) yüksek düzey duygusal zekaya sahip olan kişilerin duygu regulasyonu sürecine örgütsel gösterim kurallarını hayata geçirmek için etkin bir şekilde girebileceklerini ifade etmektedir. Côté (2005) yüksek duygusal zekası olan insanların, kişilerarası ilişkilerde derin rol yapma stratejisini rahatlıkla devreye sokabildiğini belirtmektedir. Araştırmanın sonucunda mesleki farklılıklara dayalı duygusal emek stratejileri ile ilişki ortaya çıkan bulguların profesyonellerin duygusal zeka düzeyleri ile de ilişkili olabileceği düşünülebilir.

Araştırmaya katılan kişiler, sahip oldukları mesleklere göre Psikolojik Sermaye Ölçeğinden aldıkları toplam puan ortalamaları yönünden karşılaştırıldığında psikolojik danışmanların toplam psikolojik sermaye puanının diğer 
meslek gruplarından anlamlı şekilde yüksek olduğu gözlenmiştir. Buradan yola çıarak psikolojik sermayenin duygulanım kurallarından, mesleki rollerden etkilendiği düşünülebilir. Diğer meslek gruplarıyla karşılaştırıldığında psikolojik danışmanların derin rol yapma stratejisini benimseme eğilimi olduğu ortaya çıkmıştır. Derin rol yapma, kişinin örgütsel normlara uygun olarak oluşturduğu duyguyu ifade etmesidir (Lam ve Chen, 2012). Çeşitli yazarlar derin rol yapma boyutunun, yüzeysel rol yapma boyutuna göre daha az zorlayıcı olduğunu öne sürmektedirler (Goldberg ve Grandey, 2007; Ma ve Huang, 2006). Derin rol yapma süreci sonucunda çalışan, hizmet alan kişi tarafından olumlu geri bildirim almaktadır, çalışanın özyeterliliği yükselmektedir ve başarı hissi artmaktadır. Bu sebepten, derin rol yapmanın işlevsel yönünün olduğu, çalışanın işine yarayan bir düzenleme stili olduğu düşünülmektedir (Grandey, 2003; Brotheridge ve Grandey, 2002; Brotheridge ve Lee, 2002; Cheung, Tang ve Tang, 2011). Psikolojik danışmanların derin rol yapma düzeylerinin ve psikolojik sermaye düzeylerinin arasındaki ilişki ilerleyen çalışmalarda incelenmeye değerdir.

Katılımcıların mesleklerine göre PERMA-TR Ölçeği'nden aldıkları ortalama puanlar karşılaştırıldığında anlamlı fark bulunmamıştır. Alan yazındaki çalışmalar incelendiğinde yüzeysel rol yapma stratejisinin duygusal tükenmişlikle pozitif yönde ilişkili olduğu görülmektedir (Brotheridge ve Grandey, 2002; Grandey, 2003; Totterdell ve Holman, 2003). Bu bilgiden yola çıkarak, yüzeysel rol yapma puanı anlamlı düzeyde yüksek olan psikiyatri hekimlerinin diğer meslek gruplarına göre düşük düzeyde PERMA puanı alacağı beklenebilirdi. O halde bu araştırmada incelenmemiş meslekten elde edilen gelir düzeyi, ekonomik iyi oluş, iş özellikleri değişkenlerinin incelenmesi uygun olabilir. Örneğin çalışma şartlarının, çalışan kişilerin duygusal emek stratejileri, psikolojik sermaye ve psikolojik iyi oluş üzerindeki etkilerinin incelenmesi farklı bilgiler elde edilmesini sağlayabilir. Örnek vermek gerekirse bir gün içinde kaç danışan/hasta ile görüşme yapıldığı, görüşmelerin kaç dakika sürdüğü, ruh sağlığı çalışanının bulunduğu kurumda performansının hangi kriterlerle değerlendirildiği gibi faktörlerin çalışanlar tarafından benimsenen duygusal emek stratejilerini ve psikolojik iyi oluşlarını etkileyebileceği düşünülebilir.

Mevcut araştırma, ruh sağlığı çalışanlarının meslekler arası ve çalışma şartları açısından ne çeşit örgütsel problemlerle karşılaştıklarını ve bu prob- 
lemlerin iyi oluşlarına etkileri hakkında fikir sunmamaktadır. Bu konuda yapılacak niteliksel bir araştırma, ruh sağlığı çalışanlarının çalışma hayat kalitesinin ve buna bağlı olarak iyi oluşun nasıl artırılabileceği sorusuna cevap sunabilecektir. Sağlık çalışanlarının iyi oluşuna etki eden örgütsel ve bireysel faktörlerin araştırılması hizmet performasına ve çalışanların yaşamdan aldığ 1 memnuniyete katkı sağlayacaktır. Hasta-ruh sağlığı çalışanı ilişkisi ve hizmet kalitesi sağlık çalışanlarının iyi oluşuyla pozitif yönde ilişkilidir (Scheepers, Boerebach, Arah, Heineman ve Lombarts, 2015).

Özellikle son dönemlerde sağlık çalışanlarına yönelik şiddetin yaygın olduğu gerçeği dikkat çekmektedir. Pınar ve arkadaşları (2017) sağlık sektörünün, şiddetin yaygın olarak karşılaşıldığı alanlardan biri olduğunu ifade etmişlerdir. Yaptıkları araştırmada Türkiye'de sağlık çalışanı olarak görev alan kişilerin son 12 ayda şiddetle karşılaşma oranı $44.7 \%$ olarak tespit edilmiştir. Sağlık sistemi, kurumun tipi, cinsiyet, yaş, çalışma saatleri, vardiyalı çalışma gibi faktörler iş yerinde şiddetle karşılaşma açısından risk faktörleri olarak değerlendirilmişlerdir. Dolayısıyla, ilerleyen araştırmalarda ruh sağlı̆̆ çalışanlarının psikolojik sermayelerini artıracak bireysel ve örgütsel düzeyde faktörlerin araştırılması sağlık sektöründe şiddetle mücadelede ve kişinin geneliyi oluşunu koruma açısından önem taşımaktadır. Ayrıca, sağlık alanında hizmet alan kişilerin sağlık çalışanlarından beklediği duygulanım kuralları, sosyal, mesleki roller ve sağlık çalışanlarının kendi meslekleriyle ilgili mesleki rol algılarının araştırmacılar tarafından incelenmesi hizmet performansının artırılmasına ve sağlıkta şiddet konusunda atılacak adımlara zemin oluşturabilir. 


\title{
EXTENDED ABSTRACT
}

\section{A Comparison of Mental Health Workers in Terms of Various Variables: Emotional Labor, Psychological Capital and Well-being}

\author{
Merve Mamac1 \\ İstanbul Kent University
}

The concepts of emotional labor, psychological capital and psychological well-being are frequently examined in the fields of Industrial - Organizational Psychology and Social Psychology. On the other hand it is seen that there is no adequate research covering mental health professionals in terms of these topics. It can be said that evalution of emotional labor strategies, PsyCap and psychological well-being levels of mental health workers is needed and carries an important role developing for better mental health services and developing employees.

Within the framework of industrial and organizational psychology psychological capital, is considered as an individual resource which has positive correlation with business results. The psychological capital of individuals is defined as a structure that provides long-term competitive advantage for individuals and the organizations they work with and is open to development (Luthans and Youssef, 2004). Psychological capital can be defined as a structure consists of four different sub-dimensions and these sub-dimensions are; self-efficacy, hope, optimism and resilience. On the other hand, it is stated that psychological capital is a different and comprehensive concept than the sum of these four sub-dimensions (Luthans, Avolio, Avey, and Norman, 2007).

Another concept that can be associated with the professional lives of mental health workers is emotional labor. The concept of emotional labor first introduced into the terminology by Hochschild (1979, 1983).According to Hochschild (1983) emotional labor is the regulation of an individual's individual feelings according to the appropriate norms within the framework of his profession and the organization he is in. In the emotional labor process, a person arranges his bodily expressions and gestures according to the norms. This 
effort made by the individual is also of economic value because it is made to achieve organizational goals.

As in every profession, also in mental health sector "well-being" is an important concept for workers. The World Health Organization (1998) defines health as "not only the absence of any disease or disorder, but also a state of complete mental, physical, mental and social well-being".

In a historically point of view it can be said that philosophers and psychologists are studying on similar topics. Also "well-being" is also studied by psychologists, drawing on the ideas of philosophers (Kahneman, 1999; Waterman, 1993). There are two main approaches in psychological well-being theories; hedınic and eudaimonic well-being. Hedonia reflects the urge for seeking pleasure (Huta, Park, Peterson, and Seligman, 2006) and is named as "subjective well-being" in the field of psychology (Diener and Ryan, 2009). Subjective well-being is composed of positive and negative affect, cognition (one's evaluation of living spaces and having an opinion about satisfaction) (Diener, 2009). Eudaimonia expresses the ideal functionality of the individual and the effort to reach meaningful goals in life (Huta, Park, Peterson, and Seligman, 2006). Its is important to note that psychological well-being can also be explained by the combination of hedonic and eudaimonic factors (Keyes, 2007). Althouh psychological well-being is studied by different authors and approaches, PERMA model (Seligman, 2011) attracts attention by means of covering both eudaimonic aspect and hedonic aspect of psychological wellbeing.

In this research, mental health worders such as; psychologists, psychotherapists, psychological counselors (school psychologists) and psychiatrists were studied as sample. One demographic form and three scales were used to assess emotional labor strategies (Basım and Beğenirbas, 2012; Çetin ve Basim, 2012; Demirci, Eksi, Dincer and Kardas, 2017). Data were collected in Istanbul between January and October 2018. The research consent form, demographic form and the scales were distributed to the people who wanted to participate. The scales were received at the end of the same day, together with the consent forms filled out by the participants.

The data collected in accordance with the aims of the study were subjected to statistical analysis with the SPSS v.21 (Statistical Package for Social Sciences) program. 
Demographic information was divided into categories and their distribution was calculated by frequency analysis. Before analysis, KolmogorovSmirnov and Shapiro Wilk normality test was applied and normal distribution was not observed. Skewness and Kurtosis values were observed to be between -1.5 and +1.5 . The comparison of the average scores of the participants according to their professions from the scales was made using the Kruskal Wallis test and the Mann Whitney $U$ test.

Results showed that; there is a significant difference between the average scores of the participants on the surface acting and deep acting subscale in terms of emotional labor strategies. Also a significant difference was found between the total mean scores of mental health professionals from the Psychological Capital Scale in accordance with their profession. On the other hand, when the participants were evaluated according to their professions in terms of their average scores on the PERMA scale, it was observed that there was no significant difference between professions.

\section{Kaynakça / References}

Arikan, S. ve Çankır, B. (2019). Gıda ve finans sektöründe çalışan performansı hangi faktörlerden etkileniyor? Sürdürülebilir kalite algısı, psikolojij iyi oluş ve çalş̧maya tutkunluk değişkenlerinin rolü. Uluslarası Toplum Araştırmalan Dergisi, 12(18), 1-22.

Aristotle. (1985). Nicomachean ethics. Indianapolis: Hackett.

Ashforth, B. E. ve Humphrey, R. H. (1993). Emotional labor in service roles: The influence of identity. The Academy of Management Review, 18(1), 88-115.

Avcl, A. ve Bozgeyikli, H. (2017). Okul yöneticilerinin yönetici kaygı düzeylerinin yordayıcısı olarak psikolojik sermaye. Marmara Üniversitesi Atatürk Eğitim Fakültesi Eŏitim Bilimleri Dergisi, 45, 43-57.

Bandura, A. (1997). Self-efficacy: The exercise of control. New York: Freeman.

Basım, H.N. ve Beğenirbaş, M. (2012). Çalışma yaşamında duygusal emek: Bir ölçek uyarlama çalışması. Yönetim ve Ekonomi Dergisi: Celal Bayar Üniversitesi İktisadi ve İdari Bilimler Fakültesi, 19(1), 77-90.

Çankır, B. (2019). Çağrı merkezi sektöründe çalışanların öz-yeterlilik, çalışma değerleri, içsel motivasyonları ve bir araştrma. Çukurova Araştrrmaları, 5 (2), 241-249.

Cankir, B. veŞahin, S. (2018). Medya-kültür ve sanat alanında çalışanların psikolojik iyioluşları ile işten ayrılma arasındaki ilişkide çalışmaya tutkunluğun aracı rolü. Uluslararası İktisadi ve İdari İncelemeler Dergisi, 333-346. 
Brotheridge, C. ve Grandey, A. A. (2002). Emotional labor and burnout: Comparing two perspectives of "people work". Journal of Vocational Behavior, 60, 17-39.

Brotheridge, C. M., ve Lee, R. T. (2002). Testing a conservation of resources model of the dynamics of emotional labor. Journal of Occupational Health Psychology, 7, 57-67.

Butler, J. ve Kern, M. L. (2016). The PERMA-Profiler: A brief multidimensional measure of flourishing. International Journal of Wellbeing, 6(3), 1-48.

Çetin, F. ve Basım, H. N. (2012). Örgütsel psikolojik sermaye: Bir ölçek uyarlama çalışması. Amme İaresi Dergisi, 45(1), 121-137.

Cheung, F., Tang, C. S.K., ve Tang, S. (2011). Psychological capital as a moderator between emotional labor, burnout, and job satisfaction among school teachers in China. International Journal of Stress Management, 18, 348-371.

Côté, S. (2005). Do emotionally intelligent peoplemanage their emotions wisely? Robin Gosserand and James Diefendorff (Chairs), Toward a Better Understanding of Emotion Regulation at Work. Symposium conducted at the 20th annual conference of the Society for Industrial and Organizational Psychology, Los Angeles, CA.

Demir, S. (2018). The Relationship between Psychological Capital and Stress, Anxiety, Burnout, Job Satisfaction, and Job Involvement. Eurasian Journal of Educational Research, 18(75), 137-154.

Demirci, İ., Ekşi, H., Dinçer, D. ve Kardaş, S. (2017). Beş boyutlu iyi oluş modeli: PERMA Ölçeği'nin Türkçe formunun geçerlik ve güvenirliği. The Journal of Happiness $\mathcal{E}$ Well-Being, 5(1), 60-77.

Diefendorff, J. M., Croyle, M. H., ve Gosserand, R. H. (2005). The Dimensionality and Antecedents of Emotional Labor Strategies. Journal of Vocational Behavior, 66, 339-357.

Diener, E. (2009). Subjective well-being. E. Diener (Ed.), The science of well-being: The collected works of Ed Diener, içinde (Vol. 37, s. 11-58). New York: Springer.

Diener, E, ve Ryan, K. (2009). Subjective well-being: A general overview. South African Journal of Psychology, 39(4), 391-406.

Grinde, B. (2012). The Biology of Happiness. New York: Springer.

Kashdan, T. B., Biswas-Diener, R., ve King, L. A. (2008). Reconsidering happiness: the costs of distinguishing between hedonics and eudaimonia. The Journal of Positive Psychology, 3(4), 219-233.

Keyes, C. L. ve Annas, J. (2009). Feeling good and functioning well: distinctive concepts in ancient philosophy and contemporary science. The Journal of Positive Psycho$\log , 4(3), 197-201$. 
Groth, M., Hennig-Thurau, T., ve Walsh, G. (2009). Customer reactions to emotional labor: The roles of employee acting strategies and customer detection accuracy. Academy of Management Journal, 52(5), 958-974.

Grandey, A. A. (2003). When "the show must go on": Surface acting and deep acting as determinants of emotional exhaustion and peer-rated service delivery. Academy of Management Journal, 46, 86-96.

Goldberg, L. S ve Grandey, A. A. (2007). Display rules versus display autonomy: Emotion regulation, emotional exhaustion, and task performance in a call center simulation. Journal of Occupational Health Psychology, 12, 301-318.

Henderson, L.W. ve Knight, T. (2012). Integrating the hedonic and eudaimonic perspectives to more comprehensively understand wellbeing and pathways to wellbeing. International Journal of Wellbeing, 2(3), 196-221.

Hochschild, A. (1979). Emotion work, feeling rules, and social structure. American Journal of Sociology, 85, 551-575.

Hochschild, A. (1983). The managed heart: Commercialization of human feeling. Berkeley: University of California Press.

Huta, V., Park, N., Peterson, C., ve Seligman, M. (2006). Pursuing pleasure versus eudaimonia: Links with different aspects of well-being. Yayınlanmamış metin.

Kahneman, D. (1999). Objective happiness. D. Kahneman, E. Diener, ve N. Schwarz (Ed.), Well-being: The foundations of hedonic psychology, içinde (s. 3-25). New York: Sage.

Keyes, C. L. M. (2007). Promoting and protecting mental health as flourishing: A complementary strategy for improving national mental health. American Psychologist, 62, 95-108.

Korkmazer, F., Ekingen, E. ve Yıldız, A. (2016). Psikolojik sermayenin çalışan performansına etkisi: Sağllk çalışanları üzerinde bir araştırma. Hacettepe Sağ lk İdaresi Dergisi, 19(3), 271-281.

Lam, W., ve Chen, Z. (2012). When I put on my service mask: determinants and outcomes of emotional labour among hotel service providers according to affective event theory, International Journal of Hospitality Management, 31(1), 3-11.

Lui, Y., Prati, L.M., Perrewe, P., ve Brymer, R.A. (2010). Individual Differences in Emotion Regulation, Emotional Experiences at Work, and Work-related Outcomes: A Two-Study Investigation. Journal of Applied Social Psychology, 40(6), 1515-1538.

Luthans, F. ve Youssef, C. M. (2004). Human, Social, and now positive psychological capital management: Investing in people for competitive advantage. Organizational Dynamics, 33(2), 143-160. 
Luthans, F., Avolio, B. J., Avey, J. B., ve Norman, S. M. (2007). Positive psychological capital: Measurement and relationship with performance and satisfaction. Personnel Psychology, 60, 541-572.

Ma, S. ve Huang, M. (2006). Emotional labor: Surface acting and deep acting, which one is better? Acta Psychologica Sinica, 38, 262-270.

Masten, A. S. (2001). Ordinary magic: Resilience processes in development. American Psychologist, 56, 227-238.

McDowell, J. (1980). The role of eudaimonia in Aristotle's ethics'. A. O. Rorty (Ed.), Essays on Aristotle's ethics içinde (s. 359-376). Berkeley: University of California Press.

Morris, J. A. ve Feldman, D. C. (1996). The dimensions, antecedents and consequences of emotional labor. Academy of Management Review, 21, 986-1010.

Norton, D. L. (1976). Personal destinies. Princeton: Princeton University Press.

National Center for O*NET Development. 19-3033.00 - Clinical and Counseling Psychologists. O*NET OnLine. https://www.onetonline.org/link/summary/19$\underline{3033.00}$ adresinden erişilmiştir.

O*NET OnLine (2020). National Center for O*NET Development. 19-3034.00 - School Psychologists. O*NET OnLine. https://www.onetonline.org/link/summary/19-3034.00 adresinden erişilmiştir.

O*NET OnLine (2020). National Center for O*NET Development. 29-1223.00 - Psychiatrists. O*NET OnLine. https://www.onetonline.org/link/summary/29-1223.00 adresinden erişilmiştir.

Polatçı, S. (2011). Psikolojik sermayenin performans üzerindeki etkisinde iş aile yayllmı ve psikolojik iyi oluşun rolü. Yayımlanmamış doktora tezi, Erciyes Üniversitesi Sosyal Bilimler Enstitüsü, Erciyes.

Salovey, P. ve Mayer, J. D. (1990). Emotional intelligence. Imagination, Cognition, and Personality, 9, 185-211.

Scheepers, R. A., Boerebach, B. C. M. Arah, O. A., Heineman ve Lombarts, K. M. (2015). A systematic review of the impact of physicians' occupational well-Being on the quality of patient care. International Journal of Behavioral Medicine, 22(6), 683698.

Seligman M. E. P. (2011). Flourish. New York, NY: Simon \& Schuster.

Snyder, C. R. (1994). Psychology of hope: You can get there from here. New York, NY: Free Press.

Totterdell, P. ve Holman, D. (2003). Emotion regulation in customer service roles: Testing a model of emotional labor. Journal of Occupational Health Psychology, 8, 5573. 
Waterman, A. S. (1993). Two conceptions of happiness: Contrasts of personal expressiveness (Eudaimonia) and Hedonic Enjoyment. Journal of Personality and Social Psychology, 64(4), 678-691.

Waterman, A. S. (2008). Reconsidering happiness: A eudaimonist's perspective. The Journal of Positive Psychology, 3(4), 234-252

Wong, C., ve Law, K. S. (2002). The effects of leader and follower emotional intelligence on performance and attitude: An exploratory study. Leadership Quarterly, 13(3), 243-274.

World Health Organization (1998). World Health Organization Definition of Health. http://www.who.ch/aboutwho/definition.htm adresinden erişilmiştir.

Youssef, C. M., ve Luthans, F. (2007). Positive organizational behavior in the workplace the impact of hope, optimism, and resilience. Journal of Management, 33, 774800 .

\section{Kaynakça Bilgisi / Citation Information}

Mamacı, M. (2021). Ruh sağlığı çalışanlarının çeşitli değişkenler açısından karşılaştırması: Duygusal emek, psikolojik sermaye ve iyi oluş. OPUS-Uluslararası Toplum Araştırmaları Dergisi, 17(35), 2030-2051. DOI: 10.26466/opus.801638 